\title{
Energy-Exergy Analysis of A Novel Multi-Pass Solar Air Collector With Perforated Fins
}

\author{
Mustafa Aktaşa, Adnan Sözenª, Azim Doğuş Tuncerb, Erhan Arslanc, Meltem \\ Koşan ${ }^{a}$, Osman Çürük ${ }^{a}$
}

a Energy Systems Engineering, Technology Faculty, Gazi University, Ankara, Turkey

${ }^{b}$ Energy Systems Engineering, Faculty of Engineering-Architecture, Burdur Mehmet Akif Ersoy University, Burdur, Turkey

${ }^{c}$ Insitute of Natural and Applied Science, Gazi University, Ankara, Turkey

\begin{abstract}
This work presents performance analysis of a novel multi-pass solar air collector with perforated fins (MPSACF) in winter conditions, Ankara province, Turkey. The aim of this work is to experimentally test and compare the performance of the two different design of solar collectors in the same climatic conditions. In addition, a double-pass solar air collector without fins (DPSAC) at the same absorber area was manufactured and tested as a control group. The total absorber area of both solar collectors is $0.325 \mathrm{~m}^{2}$. Thermal effects for performance improvement of the collectors have been designated. Average thermal efficiency values of DPSAC and MPSACF were calculated as $47.85 \%$ and $51.86 \%, 67.10 \%$ and $72.86 \%$, respectively in experiments performed at $0.0069 \mathrm{~kg} / \mathrm{s}(0.7$ $\mathrm{m} / \mathrm{s}$ air velocity) and $0.0087 \mathrm{~kg} / \mathrm{s}(0.9 \mathrm{~m} / \mathrm{s}$ air velocity) mass flow rates. Exergy efficiency of DPSAC and MPSACF were $2.10-17.12 \%$ and 8.74-23.97\%, respectively. Coefficient of performance (COP) values were calculated 4.63 and $4.94,3.18$ and 3.48 respectively in experiments performed at $0.0069 \mathrm{~kg} / \mathrm{s}$ and $0.0087 \mathrm{~kg} / \mathrm{s}$ mass flow rates. Although the MPSACF has high efficiency values, COP values are lower due to the presence of dual fans. Because of their high thermal efficiency, both collectors can be effectively practiced for applications such as preheating, space heating and ventilation, greenhouse heating and product drying.
\end{abstract}

(O2019. CBIORE-IJRED. All rights reserved

Keywords: Solar energy, solar collector efficiency, energy and exergy, multi-pass solar air collector, performance analysis

Article History: Received May 16 th 2018; Received in revised form October 16 th 2018; Accepted January $6^{\text {th }}$ 2019; Available online

How to Cite This Article: Aktaş, M., Sözen, A., Tuncer, A.D., Arslan, E., Koşan, M., Çürük, O. (2019) Energy-exergy analysis of a novel multipass solar air collector with perforated fins. International Journal of Renewable Energy Development, 8(1), 47-55.

http://dx.doi.org/10.14710/ijred.8.1.47-55

\section{Introduction}

Fossil fuel consumption is known to cause global warming and climate change in our world. The fact that fossil fuels will soon be consumed is turning researchers into the development and implementation of systems based on renewable energy sources. The United Nations (UN) is encouraging the clean and sustainable energy initiatives under the Sustainable Development Goals (SDG). In addition, the European Union has announced its 20-20-20 targets to be met by 2020 in order to protect the environment against the global warming problem and to prevent the adverse effects of fossil fuels (Kareem et al., 2017). The most effective way to reduce fossil fuel consumption and thus global warming is to increase the availability of renewable energy systems.

Solar thermal systems are inexpensive and simple applications and are preferred both as industrial and domestic us because of their convenience of applicability. Solar air collectors/heaters (SAC/SAH) are systems that turn solar radiation to useful heat. This is a worldwide accepted and used system that helps reduce fossil fuel consumption. In addition, solar air collectors are useable in many different field of applications to help reduce global carbon emissions. The reason for this is that they usually work with low energy consuming auxiliary equipments such as fans and so forth. With this feature, solar air collectors benefit from fulfilling the relevant criteria in green building certification systems.

There are many works in the literateur to improve the productivity of SACs/SAHs. Blowmik and Amin introduced a novel system to improve the thermal efficiency of SACs. Accordingly, it is desired to increase the reflection ratio with the reflectors added to the collector. $10 \%$ increase in thermal efficiency was achieved with the use of reflector (Blowmik and Amin, 2017). Othman et al (2005) developed and manufactured a PV-T collector with the modifications of double-pass flow, CPC (compound parabolic concentrator) and fins attached to the system to increase the efficiency. The total efficiency was $39-70 \%$ in $0.015-0.16 \mathrm{~kg} / \mathrm{s}$ mass flow rate (Othman et al., 2005). Ozgen et al (2009) transformed aluminum beverage cans as fins to increase the solar air heaters performance which is designed as double-pass. 
Aluminum beverage cans entrained to the upper and lower flow ducts of the heater. Thermal efficiency values ranged between $31 \%$ to $\% 55$. Gill et al (2013) tested three different type of solar air heater. Average first-law efficiency value of single glazed collector was $30.29 \%$, double glazed collector was $45.05 \%$ and packed bed collector was $71.68 \%$. Fudholi et al. studied the annual cost of with and without fins double pass solar collectors at different mass flow rate (Fudholi et al., 2013). Priyam and Chand (2017) theoretically investigated thermal and thermohydraulic performances at various wave lengths and amplitudes of a SAH with modifications of wavy fins. The thermal efficiency obtained as $73.2 \%$ at a mass flow rate of $0.061 \mathrm{~kg} / \mathrm{s}$ for 0.5 and $2.5 \mathrm{~cm}$ amplitude range, and $78.8 \%$ at a wavelength of $3 \mathrm{~cm}$. Hosseini et al (2018) theoretically studied SAHs with longitudinal fins as elliptical, triangular and rectangular using finite volume method. They stated that the first-law efficiency of SAH with rectangular fins is $5.5 \%$ and $12.5 \%$ higher than triangular and elliptical fins, respectively (Hosseini et al., 2018). Şevik developed a novel drying system with a double-pass SAC, a heat pump and a photovoltaic unit. As a result, the drying system can be used without any necessity for a heat pump under normal conditions (Şevik, 2013). Alta et al (2015) experimentally examined the exergetic efficiency of a SAH with a flat-plate absorber plate at air flow rates of 2,3 and $4 \mathrm{~m} / \mathrm{s}$. An experimental set was created in the study and the experimental findings were contrasted with the numerical analysis results. Hernandez and Quinonez (2018) have experimentally investigated the model for natural convection-driven, double-pass SAC. The instantaneous thermal efficiency curve of the system is determined and a new correlation is obtained to extrapolate the average convective coefficients by natural convection (Hernandez and Quinonez, 2018). Naphon (2005), calculated the thermal efficiency of the finned SAC with double-pass flow as $30-60 \%$ in theoretical work. Lesny et al (2018) experimentally examined the change in the outlet temperature of a vertically positioned SAC due to solar irradiance. According to the results, collector efficiency varies between $42-46 \%$ (Lesny et al., 2018). Omati studied to investigate various effects for tomato drying application with solar air heater. As a result of the study, tomatoes were dehumidified its moisture content $67 \%$ on wet basis (Olimat, 2017). Azaizia et al. (2017) therotically and experimentally investigated a novel greenhouse drying system which consists a solar air collector. The thermal efficiency of the collector ranged between 50-65\% (Azaizia et al, 2017).

In this study, it was purposed to investigate the performance of the fin and lower flow channel modifications on the solar air collector (MPSACF) by comparing the performance with the other manufactured double-pass collector without fins (DPSAC).

\section{Theoretical Analysis}

The collector efficiency factor $\left(F^{\prime}\right)$ means the effect of heat transfer on the collectors. Physically, it is described as the ratio of the coefficient of fluid transfer between the working fluid and the environment. It is difficult to describe these variables alone. Therefore, both variables are defined as optical efficiency $\left(\eta_{o}\right)$ and can be found with Equation 1.

$$
\eta_{\mathrm{o}}=\mathrm{F}^{\prime}(\tau \alpha)_{\mathrm{eff}}
$$

Here, $(\tau \alpha)_{e f f}$ is multiplied by the effective transmissivity-absorptivity. $\tau$ (\%); transmissivity of the solar radiation of the collector glass and $\alpha(\%)$; is described as solar radiation absorption coefficient of the absorber plate. As the temperature difference between the absorber surface and the ambient temperature increases, the thermal losses also increase. The total heat loss coefficient $\left(U_{L}\right)$, is defined on the basis of the absorbent surface temperature. Equation 2 can be used to find the total heat transfer coefficient.

$\mathrm{U}_{\mathrm{eff}}=\mathrm{F}^{\prime} \mathrm{U}_{\mathrm{L}}$

Here, $U_{\text {eff }}$ is the effective heat loss coefficient $\left(\mathrm{W} / \mathrm{m}^{2} \mathrm{~K}\right), U_{L}$ is the total heat loss coefficient $\left(\mathrm{W} / \mathrm{m}^{2} \mathrm{~K}\right)$, and $F^{\prime}$ is the collector efficiency factor (-).

Some of the energy coming from the absorber plate is stored in the collector, and the remaining part disappears into the surroundings due to radiation, convection, and conduction. The total heat loss coefficient $\left(U_{L}\right)$, is equal to the sum of the heat losses from the upper and the bottom surface of the collector.

$\mathrm{U}_{\mathrm{L}}=\mathrm{U}_{\mathrm{T}}+\mathrm{U}_{\mathrm{b}}$

The overall heat loss coefficient at the collector surface is formed by radiation and convection losses. The upper heat loss coefficient is given in Equation 4 (Klein, 1975).

$$
\begin{aligned}
& \mathrm{U}_{\mathrm{T}}=\left\{\frac{\mathrm{N}}{\left.\frac{\mathrm{C}}{\mathrm{T}_{\mathrm{p}}}\left[\frac{\left(\mathrm{Tp}-\mathrm{T}_{\mathrm{a}}\right)}{(\mathrm{N}+\mathrm{f})}\right]^{\mathrm{e}}+\frac{1}{\mathrm{~h}_{\mathrm{w}}}\right\}^{-1}+}\right. \\
& \frac{\sigma\left(\mathrm{T}_{\mathrm{p}}+\mathrm{T}_{\mathrm{a}}\right)\left(\mathrm{T}^{2}{ }_{\mathrm{p}}+\mathrm{T}^{2} \mathrm{a}\right)}{\left(\varepsilon_{\mathrm{p}}+0.00591 \mathrm{Nh}_{\mathrm{W}}\right)^{-1}+\frac{2 \mathrm{~N}+\mathrm{f}-1+0.33 \varepsilon_{\mathrm{p}}}{\varepsilon_{\mathrm{g}}}-\mathrm{N}}
\end{aligned}
$$

In order for the upper heat loss coefficient to be found, the variables in Equation 4 need to be known. In Equation $4, N$ is the number of collector cover, $\varepsilon_{\mathrm{g}}$ is the emissivity coefficient of collector cover (-), $\varepsilon_{\mathrm{p}}$ is the emissivity coefficient of absorber plate (-), $\mathrm{T}_{\mathrm{p}}$ is the temperature of the absorber plate $(\mathrm{K}), \mathrm{T}_{\mathrm{a}}$ is ambient temperature $(\mathrm{K})$ and $\sigma$ is Stefan-Boltzmann constant $\left(5.6703 \times 10^{-8} \mathrm{~W} / \mathrm{m}^{2} \mathrm{~K}^{4}\right)$.

$$
\begin{aligned}
& C=520\left(1-0.000051 \beta^{2}\right), \quad \beta=70^{\circ} \\
& \text { if } 0^{o}<\beta<70^{\circ} \\
& \mathrm{F}=\left(1+0.089 \mathrm{~h}_{\mathrm{w}}-0.1166 \mathrm{~h}_{\mathrm{w}} \varepsilon_{\mathrm{p}}\right) \\
& e=0.4301-100 / T_{p} \\
& h_{w}=5.7+3.8 V_{r}
\end{aligned}
$$


The expression $h_{w}$ in Equation 7 is the convective heat transfer coefficient of air on the outer surface of the collector glass $\left(\mathrm{W} / \mathrm{m}^{2} \mathrm{~K}\right)$ and $V_{r}$ is the wind speed $(\mathrm{m} / \mathrm{s})$. The lower heat loss coefficient is given in Equation 9 below:

$$
\mathrm{U}_{\mathrm{b}}=\mathrm{k}_{\mathrm{i}} / \mathrm{L}_{\mathrm{b}}
$$

$k_{i}(\mathrm{~W} / \mathrm{mK})$ is the heat transfer coefficient of the material which is used for thermal insulation and $L_{b}(\mathrm{~m})$ is the thickness of lower thermal insulation material.

Energy achieved in solar air collector can be found as follows;

$\dot{Q}_{S A C}=\dot{V}_{S A C} \cdot \rho \cdot C \cdot\left(T_{o}-T_{i}\right)$

Here, $\dot{V}_{S A C}$ is volumetric flow rate of the working fluid/air $\left(\mathrm{m}^{3} / \mathrm{s}\right), T_{i}$ is temperature of inlet air $(\mathrm{K})$ and $T_{o}$ is temperature of outlet air $(\mathrm{K})$. The specific heat capacity $(\mathrm{kJ} / \mathrm{kgK})$ of air can be defined (Zare et al., 2006);

$$
\mathrm{C}=1009.26-0.0040403 \cdot \mathrm{T}+0.0061759 \text {. }
$$

$\mathrm{T}^{2}-0.0000004097 \cdot \mathrm{T}^{3}$

The gas density decreases with increasing temperature. The density of the air inlet is calculated with Equations 12 and 13.;

$$
\begin{aligned}
& P \cdot V=m \cdot R \cdot T \\
& \rho_{i}=\frac{P}{R \cdot T_{i}}
\end{aligned}
$$

Here $\mathrm{P}$ is the absolute air pressure $(\mathrm{kPa}), \mathrm{V}$ is the air volume (m3), $\mathrm{m}$ is mass of air (kg), $\rho \_\mathrm{i}$ is density of inlet air $(\mathrm{kg} / \mathrm{m} 3)$ and $R$ is gas constant $(\mathrm{kJ} / \mathrm{kgK})$. For air, a fully developed turbulence flow between planar plates can be written as in Equation 14 (Kays, 1966).

$$
\mathrm{Nu}=\mathrm{hL} / \mathrm{k}=0.0158 \mathrm{Re}^{0.8}
$$

Reynolds number can be defined as follows;

$$
\operatorname{Re}=D_{\mathrm{e}} \nu \rho / \mu
$$

The energy amount gained by the DPSAC and MPSACF was measured with the solarmeter (pyranometer) instantaneously. The instantaneous thermal efficiency of collector (\%) is expressed;

$\eta=\frac{\dot{V}_{S A C} \cdot \rho \cdot C \cdot\left(T_{o}-T_{i}\right)}{A_{S A C} I}$

Here $A_{S A C}$ is the surface area of the collectors absorber plate $\left(\mathrm{m}^{2}\right)$. The coefficient of performance $(\mathrm{COP})$ of the SACs can be determined by Equation 17 [11];

$C O P=\frac{\dot{Q}_{S A C}}{W_{f a n}}$

Fan power can be defined;

$\dot{W}_{\text {fan }}=V_{p} \cdot I_{l} \cdot \cos \varphi$
The fin efficiency depends on the frequency of the fin, the material used, and the area of the fin in the flow direction. The fin efficiency can be calculated by Equation 19 (Yeh, 1992). However, the corrected fin length should be used in calculations. The corrected fin length can be found with Equation 20.

$$
\begin{gathered}
\eta_{f}=\frac{\tanh \sqrt{2 h / k d} b_{c}}{\sqrt{2 h / k d}} \\
b_{c}=b+d / 2
\end{gathered}
$$

Here, $b$ is the length of the fin (m), $d$ is the height of the fin $(\mathrm{m}), \mathrm{k}$ is the conduction heat transfer coefficient and $h$ is convective heat transfer coefficient. The fin effectiveness (-) indicates how much the heat transfer will increase if the fin is added. In calculating the fin effect, the area of the bottom of the fin, i.e. the area of the fin on the absorbent plate, is considered. The heat from the fins to the air (W) is given in Equation 21 and the fin effectiveness (-) in Equation 22 (Cengel and Ghajar, 2011).

$\dot{\mathrm{Q}}_{\mathrm{f}}=\eta_{\mathrm{f}} \mathrm{h} \mathrm{A}_{\mathrm{f}}\left(\mathrm{T}_{\mathrm{p}}-\mathrm{T}_{\mathrm{d}}\right)$

$\varepsilon_{f}=\dot{Q}_{f} / h A_{w}\left(T_{p}-T_{d}\right)$

In Equation 23, $\mathrm{A}_{\mathrm{f}}$ is the bottom area of the fin $\left(\mathrm{m}^{2}\right)$ and $T_{d}$ is the temperature of the air on the upper flow channel (K). In Equation 24, $\dot{Q}_{f}$ is the transmitted energy from fin to air and $A_{w}$ is the area without fin $\left(\mathrm{m}^{2}\right)$.

The exergy analysis for SACs under the steady state, steady flow conditions can be expressed as follows;

Mass conservation of air is

$\sum \dot{m}_{i}=\sum \dot{m}_{o}$

The general energy and exergy equilibriums is obtained as

$\sum \dot{E}_{i}=\sum \dot{E}_{o}$

$\sum \dot{E} x_{i}-\sum \dot{E} x_{o}=\sum \dot{E} x_{d}$

$\dot{E} x_{d}-\dot{E} x_{\text {work }}+\dot{E} x_{m a s s, i}-\dot{E} x_{m a s s, o}=\dot{E} x_{d}$

Here, $\dot{E} x_{d}$ is destroyed exergy (W). With the use of Equation 28, the rate of the general exergy equilibrium is determined with following equation (Saxena et al., 2015);

$\sum\left(1-T_{a} / T_{s}\right) \dot{Q}_{S A C}-\dot{W}+\sum \dot{m} \psi_{i}=\dot{E} x_{d}$

Where, $\psi$ is specific exergy $(\mathrm{kJ} / \mathrm{kg})$ and $\dot{W}$ is the work rate $(\mathrm{W})$. Entropy $(\mathrm{kJ} / \mathrm{kgK})$ and the enthalpy $(\mathrm{kJ} / \mathrm{kg})$ differences of the air at the SAC can be calculated by;

$$
\begin{aligned}
& \Delta s=s_{o}-s_{i}=C \ln \left(T_{o} / T_{i}\right)-R \ln \left(P_{o} / P_{i}\right) \\
& \Delta h=h-h_{i}=C\left(T_{o}-T_{i}\right)
\end{aligned}
$$

In Equation 31, $P_{o}\left(\mathrm{~N} / \mathrm{m}^{2}\right)$ is pressure of the outlet air and $P_{i}$ is the inlet air pressure $\left(\mathrm{N} / \mathrm{m}^{2}\right)$. Exergy efficiency of a $\mathrm{SAC}(\%)$ can be expressed by; 
$\eta_{I I}=\frac{\dot{E} x_{o}}{\dot{E} x_{i}}=\frac{\dot{m}\left[\hbar_{o}-h_{i}-T_{a}\left(s_{o}-s_{i}\right)\right]}{\left(1-\left(T_{a} / T_{S}\right)\right) \dot{Q}_{S A C}}$

Here $T_{s}$ is temperature of sun $(\mathrm{K})$

\section{Materials and Methods}

\subsection{Experimental Set-up}

In this work, two different solar collectors were designed, manufactured in the same dimensions and with the same absorber plate area and tested under two different weather conditions and air velocities. DPSAC manufactured without fin, MPSACF has 12 fins on the upper flow channel. Absorber plates of the collectors were manufactured from copper plate with a thickness of 1 millimeter and painted with matt black paint. There is a fan (power: $40 \mathrm{~W}$ ) at the entrance of the DPSAC, two fans for MPSACF to provide flow. The heat insulation of collectors made to reduce the thermal losses from DPSAC and MPSACF and thus, more faultless experimental results were attained. Technical specifications of MPSACF and the measurement equipments are given in Table 1. Schematical illustration of experimental set-up is presented in Fig. 1. Sectional view of upper flow channel and lower flow channel of MPSACF is illustrated in Fig. 2. The length units which are shown in Fig. 2 are in $\mathrm{mm}$ scale.

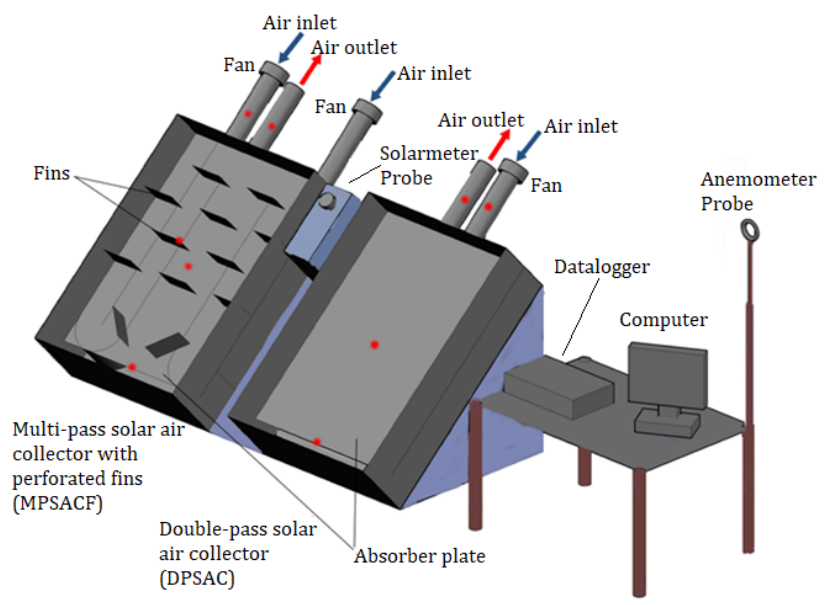

Fig. 1 Schematic illustration of experimental set-up

As it can be seen in Fig. 1, MPSACF and DPSAC have been tested on the same platform since they are intended to be at the same tilt angle. The red dots indicate where the temperature measurement is taken with thermocouples. The temperature values from different points which is measured with K-type thermocouples are recorded with the aid of a datalogger. In the experiments, an anemometer used to measure the air velocity and the other were immobilized to measure wind speed.

As it can be seen in Fig. 2 there are 12 perforated fins in the upper flow channel. In the lower flow channel, air enters with the aid of two fans and joins on the middle and continues to reach the upper flow channel. The absorber plate, fins and lower flow channel modification components of MPSACF have the same thickness and material of $1 \mathrm{~mm}$ copper. Fins were perforated in so far as increase the heat transfer area on the flow direction. Each fin has 4 round holes with 12 $\mathrm{mm}$ diameter. Specifications of DPSAC and MPSACF is presented in Table 1.
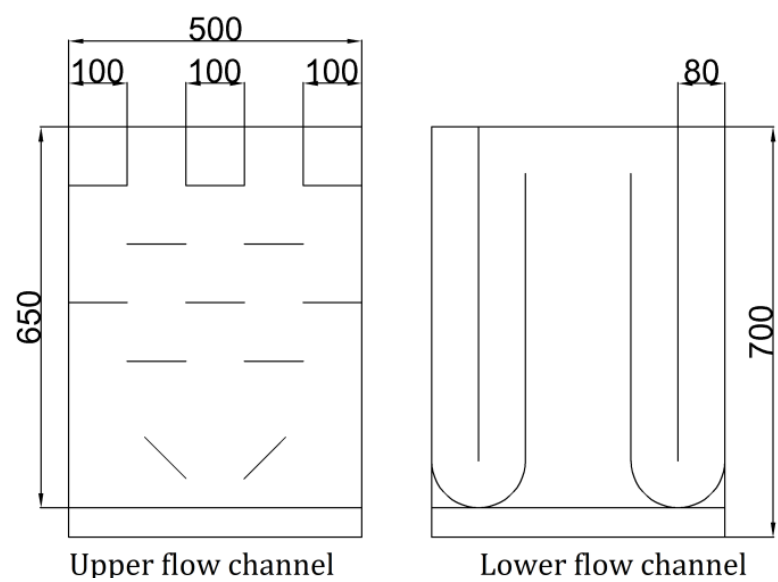

Fig. 2 Sectional view of upper flow channel and lower flow channel of MPSACF

Table 1

Specifications of DPSAC, MPSACF

\begin{tabular}{|c|c|}
\hline Equipments & Specifications \\
\hline \multirow{5}{*}{ Fan } & Manufacturer/Model: Tidar 120 x $120 \mathrm{x}$ \\
\hline & $38,220-240 \mathrm{~V} \mathrm{AC}, 40 \mathrm{~W}, 100 \mathrm{~m}^{3} / \mathrm{h}$ \\
\hline & ( 1 pcs for DPSAC, 2 pcs for MPSACF) \\
\hline & Collector cover: Glass (Thickness: 4 mm) \\
\hline & Absorber plate: Copper, 0,50 x 0,65 m, 1 \\
\hline $\begin{array}{l}\text { Solar Air } \\
\text { Collector }\end{array}$ & \\
\hline Collector & $\begin{array}{l}\text { Fins (MPSACF): Copper, } 12 \text { pcs with } 4 \\
\text { round holes }(\varnothing=12 \mathrm{~mm}), 0.06 \times 0.1 \mathrm{~m}, 1 \mathrm{~mm} \\
\text { thickness }\end{array}$ \\
\hline Insulation & $\begin{array}{l}\text { Expanded polystyrene foam, (Thickness: } 50 \\
\mathrm{~mm} \text { ), }\end{array}$ \\
\hline & $\begin{array}{l}\text { Thermal resistance: } 1.55 \mathrm{~m}^{2} . \mathrm{K} / \mathrm{W} \text {, } \\
\text { Thermal conductivity: } 0.034 \mathrm{~W} / \mathrm{mK}\end{array}$ \\
\hline
\end{tabular}

\subsection{Experimental Procedure}

The experiments were performed under two different weather conditions. Experiments were carried out in December, in Ankara province, Turkey. The first experiment was carried out on the day when the air temperature was observed at the seasonal norms for both collectors with a mass flow rate of $0.0069 \mathrm{~kg} / \mathrm{s}$. The second experiment was carried out for DPSAC and MPSACF at a mass flow rate of $0.0087 \mathrm{~kg} / \mathrm{s}$. A dimmer is used to keep the air speed constant. Before starting experiments, collectors' covers was cleaned and collectors have been overshadowed and run for ten minutes to enter the regime after being taken to the testing site, during this time all measurement equipments have been tested. The temperature measurements were collected with data-logger. Ambient conditions were measured and recorded on every 10 minutes until the experiment was finished. The solarmeter was placed in the same direction as the collectors cover to make an accurate measurement. Experiments started at 10:30 and ended at 15:30 to make an accurate comparison. The air velocity in the experiments was adjusted by means of the dimmer switch. Accordingly, the fan power was calculated for DPSAC as $25.2 \mathrm{~W}$ for $0.0069 \mathrm{~kg} / \mathrm{s}, 28.6 \mathrm{~W}$ for $0.0087 \mathrm{~kg} / \mathrm{s}$, for MPSACF as $50.4 \mathrm{~W}$ for $0.0069 \mathrm{~kg} / \mathrm{s}$, $56.4 \mathrm{~W}$ for $0.0087 \mathrm{~kg} / \mathrm{s}$. 


\section{Uncertainty Analysis}

While measuring a parameter value, the total error analysis can be calculated by Equation 24, considering faults based on firm faults, coincidental faults and production faults (Aktaş et al., 2017);

$W_{R}=\left[\left(\frac{\delta R}{\partial x_{1}} w_{1}\right)^{2}+\left(\frac{\delta R}{\partial x_{2}} w_{2}\right)^{2}+\cdots+\left(\frac{\delta R}{\partial x_{n}} w_{n}\right)^{2}\right]^{1 / 2}$

In Equation 24, $\mathrm{R}$ is a function of $\boldsymbol{x}_{1}, \boldsymbol{x}_{2} \ldots \boldsymbol{x}_{\boldsymbol{n}}$ independent variables. $\boldsymbol{W}_{\mathbf{1}}, \boldsymbol{W}_{\mathbf{2}} \ldots \boldsymbol{W}_{\boldsymbol{n}}$ values are the uncertainty of the independent variables. The specifications and accuracy values of the measuring devices used in the experiments are given in Table 2 .

Table 2

Specifications and accuracy values of measurement devices

\begin{tabular}{cll}
\hline Equipments & \multicolumn{2}{c}{ Specifications } \\
\hline \multirow{3}{*}{ Anemometer } & Manufacturer/ & Specifications: 0-20 \\
& Model: Kimo, & $\mathrm{m} / \mathrm{s}, 0.3-35 \mathrm{~m} / \mathrm{s},-20-$ \\
& VT 200 & $+80{ }^{\circ} \mathrm{C}, \pm 0,3 \mathrm{~m} / \mathrm{s}, \pm$ \\
& Manufacturer/ & $0.1{ }^{\circ} \mathrm{C}(2 \mathrm{pcs})$ \\
Specifications: 0- \\
Solarmeter & Model: Kimo, & $1300 \mathrm{~W} / \mathrm{m}^{2}, \pm 5 \%$ \\
& SL 100 & $\mathrm{W} / \mathrm{m}^{2}(1 \mathrm{pcs})$ \\
Relative humidity & Manufacturer/ & Specifications: $-40-$ \\
and temperature & Model: Ordel, & $120{ }^{\circ} \mathrm{C}, \pm 0.1{ }^{\circ} \mathrm{C}(1$ \\
sensors & HTC08 & pcs $)$ \\
K-type & Manufacturer/ & Specifications: \\
thermocouples & Model: Elimko, & Range: $-200+1200$ \\
& E-680 & ${ }^{\circ} \mathrm{C}, \pm 0.5^{\circ} \mathrm{C}(10 \mathrm{pcs})$ \\
\hline
\end{tabular}

\section{Results and Discussions}

Experiments were made to determine the performance analysis of DPSAC and MPSACF and to examine the impact of fins on collector performance. Fig. 3 shows the change in ambient temperature and solar irradiance over time. The average ambient temperatures were found 8.7 and $14.68^{\circ} \mathrm{C}$ in first and second experiment, respectively. The ambient temperature in the second experiment was above the seasonal norms. In the second experiment, mean solar radiation was higher than first experiment.

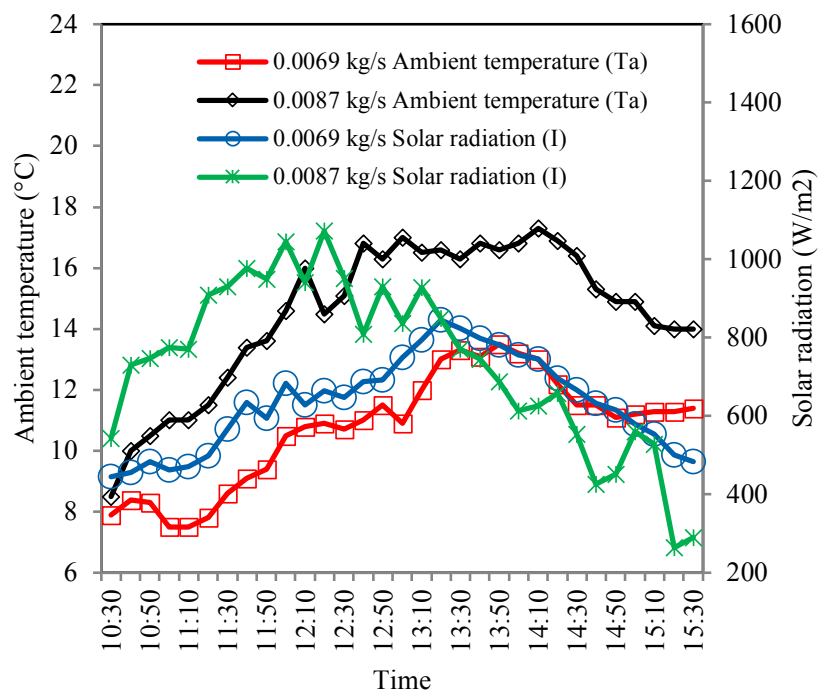

Fig. 3 Time-dependent change of ambient temperature and solar irradiance

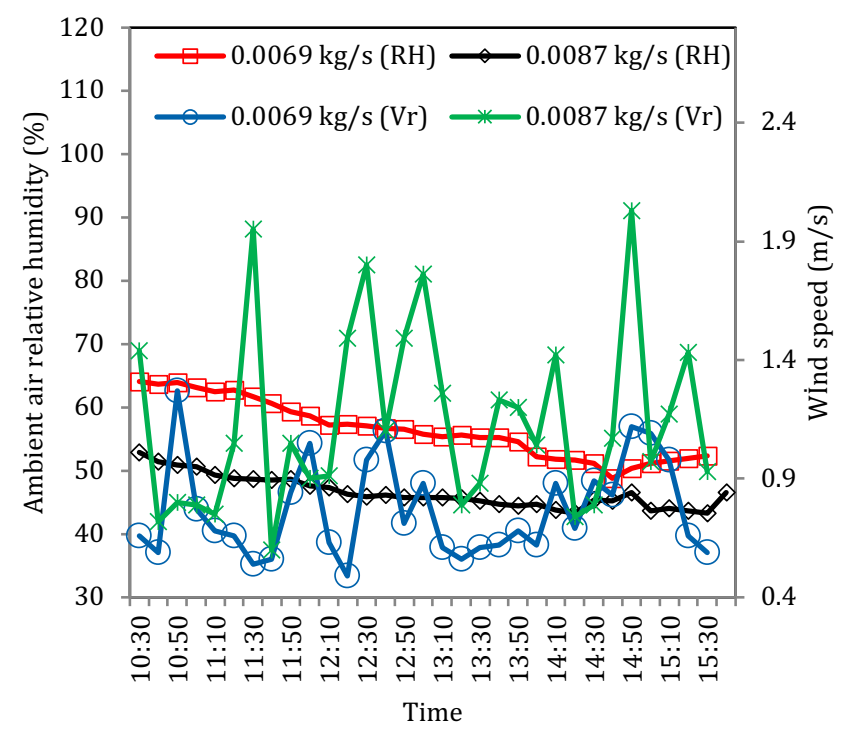

Fig. 4 Variation of the ambient air relative humidity and wind speed on time

The mean solar radiation was measured $633.39 \mathrm{~W} / \mathrm{m}^{2}$ in the first experiment and $737.84 \mathrm{~W} / \mathrm{m}^{2}$ in the second experiment. In the second experiment, although the solar radiation values were higher than the first experiment, the values fluctuated resulting from the weather was partly cloudy. After 13:30, the solar radiation decreased in both experiments.

Variation of the ambient air relative humidity and wind speed on time are given in Fig. 4. The average relative humidity in the first experiment was $56.47 \%$ and in the second experiment $46.59 \%$. Wind speed ranged from $0.49-1.27 \mathrm{~m} / \mathrm{s}$ in the first experiment which is conducted at $0.0067 \mathrm{~kg} / \mathrm{s}$, and $0.60-2.03 \mathrm{~m} / \mathrm{s}$ in the second experiment which is performed at $0.0087 \mathrm{~kg} / \mathrm{s}$. The average wind speed was measured as $0.77 \mathrm{~m} / \mathrm{s}$ in the first experiment and $1.15 \mathrm{~m} / \mathrm{s}$ in the second experiment.

Time-dependent change of temperature at the collector outlet is given in Fig. 5. The outlet temperature of DPSAC in the first experiment ranged from 12.2-32.5 ${ }^{\circ} \mathrm{C}$, in the second experiment it ranged from $14.2-35.4{ }^{\circ} \mathrm{C}$. For MPSACF, outlet temperature ranged from 17.9-38.1 ${ }^{\circ} \mathrm{C}$, in the second experiment it ranged from $19.2-43.2{ }^{\circ} \mathrm{C}$. Highest average outlet temperature obtained in the second experiment as $31.9{ }^{\circ} \mathrm{C}$ for MPSACF, as expected. In the experiment where the highest ambient exist, which conducted in $0.0087 \mathrm{~kg} / \mathrm{s}$, the highest outlet air temperature was also observed.

Time-dependent variation of temperature difference values between collector air outlet and inlet are given in Fig. 6. Temperature difference values of DPSAC and MPSACF in first and second experiments were ranged from $6.3-24.7^{\circ} \mathrm{C}$ and $11.1-30.4{ }^{\circ} \mathrm{C}, 3.4-22.5^{\circ} \mathrm{C}$ and 6.3 $31.1^{\circ} \mathrm{C}$ respectively. Average temperature difference values of DPSAC and MPSACF in first and second experiments were obtained $14.62^{\circ} \mathrm{C}$ and $20.10^{\circ} \mathrm{C}, 14.39^{\circ} \mathrm{C}$ and $20^{\circ} \mathrm{C}$ respectively. The temperature difference in the second experiment with higher mass flow rate was due to the wind speed being lower than the first experiment 


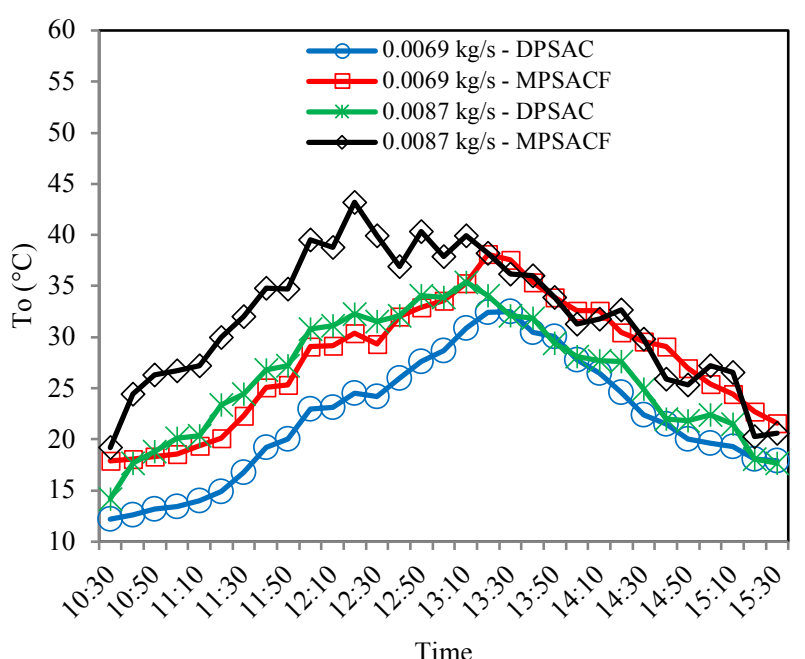

Fig. 5 Time-dependent change of temperature at the collector outlet

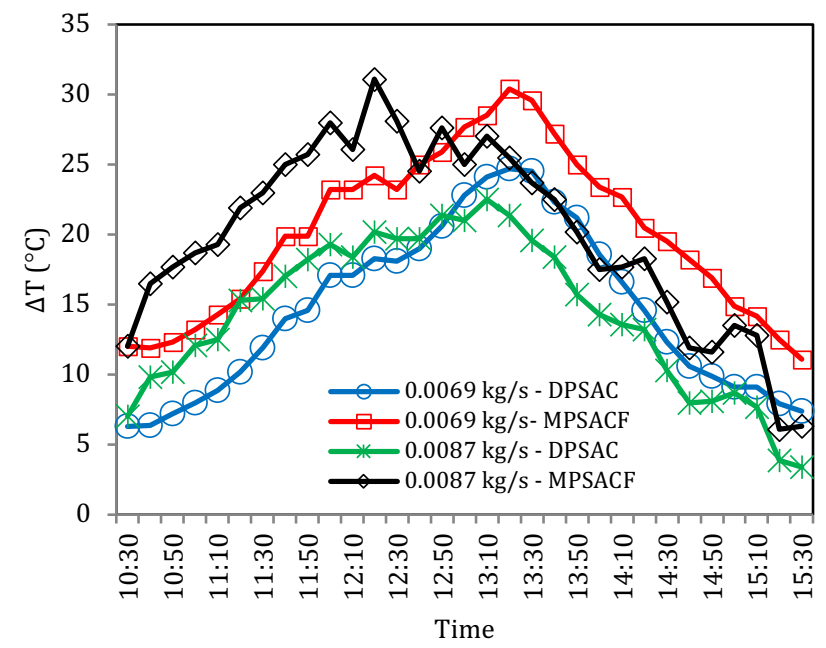

Fig. 6 Time-dependent variation of temperature difference between outlet air and inlet air of the collectors

Variation of thermal efficiency values of DPSAC and MPSACF with time are illustrated in Fig. 7. Average thermal efficiency values of MPSACF and DPSAC in first and second experiments were obtained $67.10 \%$ and $72.86 \%, 47.85 \%$ and $51.86 \%$ respectively. The maximum instantaneous thermal efficiency value was obtained as $83.47 \%$ in MPSACF in the second experiment. The thermal efficiency values in the second experiment fluctuated depending on the irregularity in the solar radiation. The reason for that is partly cloudy weather. The thermal efficiency values for both experiments were decreasing from 13:20 depending on the solar radiation.

Variation of COP values of DPSAC and MPSACF with time are illustrated in Fig. 8. Average COP values of DPSAC and MPSACF were obtained 4.05 and 4.45, 2.78 and 3.13 respectively in experiments performed at $0.0069 \mathrm{~kg} / \mathrm{s}$ and $0.9 \mathrm{~m} / \mathrm{s}$ mass flow rates. The highest COP value was seen in DPSAC as 6.84 in the first experiment. Although the MPSACF has high efficiency values, COP values are lower due to the presence of dual fans. It was observed that there is a decrease in COP values from 13:20 in direct proportion to solar radiation.

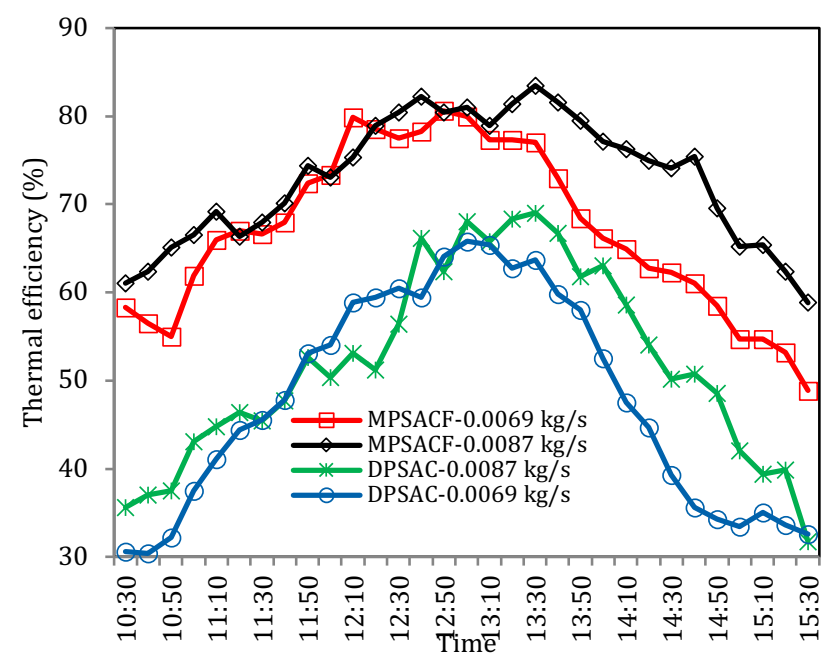

Fig. 7 Variation of thermal efficiency values of DPSAC and MPSACF with time

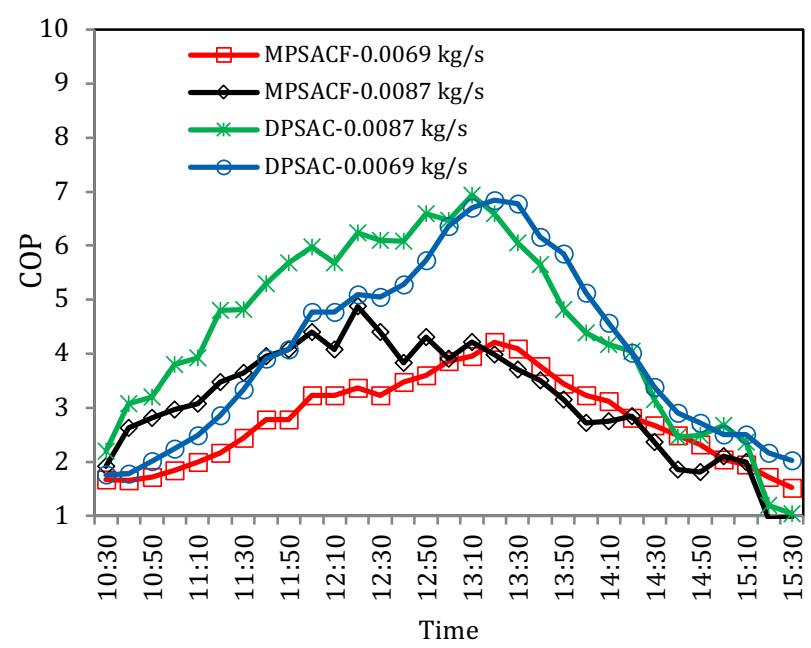

Fig. 8 Variation of COP values of DPSAC and MPSACF with time

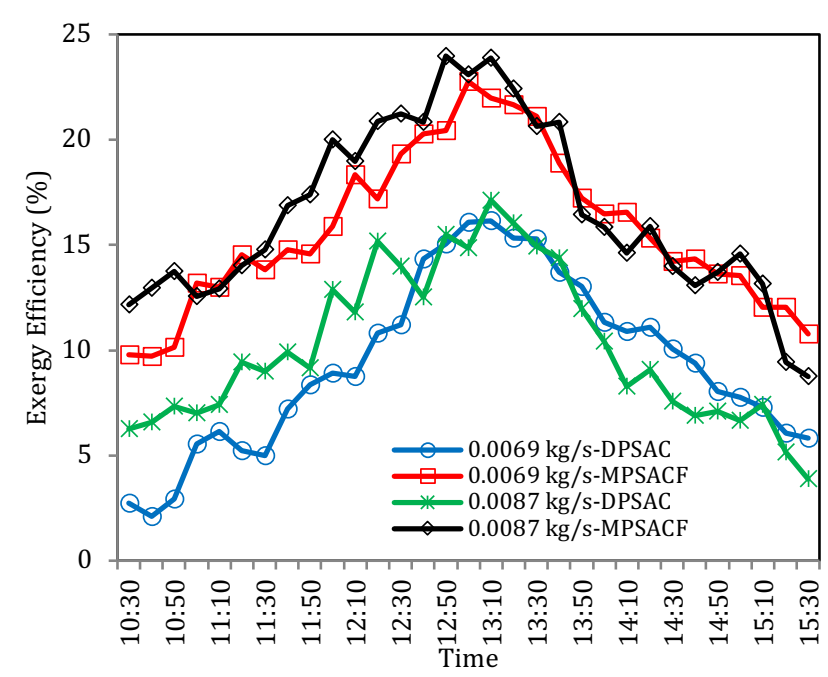

Fig. 9 Time-dependent change of exergy efficiency values of DPSAC and MPSACF

The time-dependent exergy efficiency values are presented in Fig. 9. The average exergy efficiency values 
were found $9.40 \%$ for DPSAC and $15.72 \%$ for MPSACF in the first experiment. For the DPSAC and MPSACF, the average exergy efficiency values in the second experiment were observed $10.17 \%$ and $16.56 \%$, respectively. As can be seen in the Fig. 9, the increment in the solar radiation value increases the exergy giving values for both collectors based on mass flow rate. Exergy efficiency of the collectors did not tend to increase linearly as many variables were connected. As the instant solar radiation per unit absorber area rised, the value of exergy efficiency increased validly.

The pressure drop values for DPSAC and MPSACF depending on mass flow rate is given in Fig. 10. As it was expected pressure drop significantly increases when collector with multi-pass lower air duct and perforated fins (MPSACF) are used. Also pressure drop increases by $25 \%$ for DPSAC and $23 \%$ for MPSACF as mass flow rate has a higher value.

Table 3

The uncertainty of COP and thermal efficiency values

\begin{tabular}{ccc} 
& $0.0069 \mathrm{~kg} / \mathrm{s}$ mass & $0.0087 \mathrm{~kg} / \mathrm{s} \mathrm{mass}$ \\
flow rate & flow rate \\
DPSAC COP & $\pm 0,0565$ & $\pm 0,1038$ \\
MPSACF COP & $\pm 0,1170$ & $\pm 0,2263$ \\
Thermal Efficiency of DPSAC & $\pm 0,2173 \%$ & $\pm 0,1843 \%$ \\
Thermal Efficiency of MPSACF & $\pm 0,3039 \%$ & $\pm 0,2574 \%$ \\
\hline
\end{tabular}

Table 4

Details of some studies on solar air collectors/heaters

\begin{tabular}{|c|c|c|c|c|}
\hline Ref. & Application & $\begin{array}{l}\text { Mass flow rate/air } \\
\text { velocity }\end{array}$ & $\begin{array}{l}\text { Thermal } \\
\text { efficiency }\end{array}$ & $\begin{array}{c}\text { Exergy } \\
\text { efficiency }\end{array}$ \\
\hline Abuşka and Şevik, 2017 & $\begin{array}{l}\text { Flat plate, V-groove, } \\
\text { front-pass }\end{array}$ & $0.04,0.06,0.08,0.1 \mathrm{~kg} / \mathrm{s}$ & $43-60 \%$ & $6-12 \%$ \\
\hline Ghiami and Ghiami, 2018 & $\begin{array}{l}\text { PCM assisted with } \\
\text { galvanized baffles }\end{array}$ & $0.017,0.014,0.009 \mathrm{~kg} / \mathrm{s}$ & $14.30-26.78 \%$ & $4.86-20.47 \%$ \\
\hline Tiwari and Tiwari, 2017 & PV-Thermal & $0.014-0.036 \mathrm{~kg} / \mathrm{s}$ & $42.22-61.56 \%$ & $19.11-28.98 \%$ \\
\hline Karim et al., 2014 & V-corrugated & $1-10 \mathrm{~m} / \mathrm{s}$ & $55-69 \%$ & - \\
\hline Zheng et al., 2017 & Corrugated packing & $0.32,0.48 \mathrm{~m} / \mathrm{s}$ & $47-66 \%$ & - \\
\hline Devecioglu and Oruc, 2017 & $\begin{array}{l}\text { Single-pass, porous } \\
\text { surface }\end{array}$ & $0.031-0.038 \mathrm{~kg} / \mathrm{s}$ & $25-57 \%$ & - \\
\hline \multirow[t]{2}{*}{ Aktaş et al., 2018} & $\begin{array}{l}\text { Double-pass, zigzag } \\
\text { formed absorber plate } \\
\text { with fins }\end{array}$ & - & $51.12-88.48 \%$ & - \\
\hline & Double-pass & $0.0069 \mathrm{~kg} / \mathrm{s}-0.0087 \mathrm{~kg} / \mathrm{s}$ & $30.37-69.03 \%$ & $2.10-17.12 \%$ \\
\hline This study & $\begin{array}{l}\text { Multi-pass with } \\
\text { perforated fins }\end{array}$ & $0.0069 \mathrm{~kg} / \mathrm{s}-0.0087 \mathrm{~kg} / \mathrm{s}$ & $48.88-83.47 \%$ & $8.74-23.97 \%$ \\
\hline
\end{tabular}

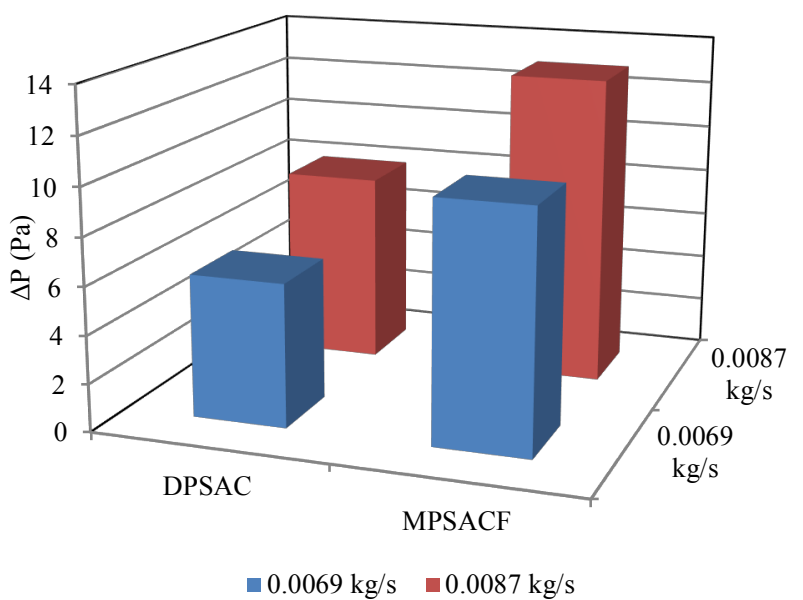

Fig. 10 The pressure drop values for DPSAC and MPSACF depending on mass flow rate 
The uncertainties of COP and thermal efficiencies were calculated by taking into account the experimental measurements are presented in Table 3. As can be seen in Table 3, the lowest uncertainty for the COP value was found as $\pm 0,0565$ in the DPSAC in the first experiment. For thermal efficiency, the lowest uncertainty was observed as $\pm 0,1843 \%$ also in DPSAC in the second experiment. Details of some studies on solar air collectors/heaters is given in Table 4.

According to Table 4, there are many different applications in this area. When this study is compared with the literature in terms of collector performance, it can be seen that superiority and acceptability in the sense of both energy and exergy efficiencies are appeared. Collector systems which designed, manufactured and tested in this study have high performance and use absorbed energy from the solar radiation effectively due to the fact that their geniune design and material.

\section{Conclusions}

In this study, two collectors with fin (MPSACF) and without fin (DPSAC) at the same absorber plate area were designed and manufactured, and the thermal performance of the collectors was analysed. As a result of experiments and analyses, the following conclusions have been reached.

- MPSACF's outlet air temperature was higher than DPSAC because of has an air channel modification in the bottom layer and a fin structure. Also, at higher temperatures of MPSACF, it resulted in having a higher thermal efficiency.

- The highest thermal efficiency was observed as $83.47 \%$ for MPSACF at the second experiment which is performed at $0.0087 \mathrm{~kg} / \mathrm{s}$ mass flow rate. According to ambient conditions such as wind velocity, ambient (environmental) temperature, ambient air relative humidity and solar radiation, the thermal efficiency for DPSAC varied from $30.37 \%$ to $69.03 \%$, for MPSACF varied from $48.88 \%$ to $83.47 \%$. Exergy efficiency of DPSAC and MPSACF were $2.10-17.12 \%$ and $8.74-23.97 \%$, respectively.

- The fan numbers in DPSAC and MPSACF are designed as one and two respectively. Therefore, COP counts were calculated separately and it was found that DPSAC had higher COP values due to having single blob. In the first experiment, the highest COP value was 7.82 for DPSAC.

- Although experiments were carried out in winter conditions, the MPSACF showed an instantaneous temperature of $43.2{ }^{\circ} \mathrm{C}$. Average temperature difference values of DPSAC and MPSACF in first and second experiments were obtained $14.62^{\circ} \mathrm{C}$ and $20.10^{\circ} \mathrm{C}, 14.39^{\circ} \mathrm{C}$ and $20^{\circ} \mathrm{C}$ respectively.

- Experiments showed that MPSACF is an alternative for hot air generation for domestic and industrial applications with regards to its high efficiency values and low energy consumption.

This study, with its advantages as high energy and exergy efficiencies and low energy consumption will contribute to the UN's 20-20-20 goals to compensate. The usage of this study which solar energy is used effectively whether it is commercial, industrial or domestic, will provide significant improvements in aforementioned buildings' decrease of carbon dioxide emissions on the green building certification systems' scoring criteria, control of the energy, energy efficient equipments, nitrogen oxide emissions originating from heating or cooling applications and provide substantial improvements on the subjects of innovation, bring light to designers and bring a new perspective to the subject matter.

\section{References}

Abuşka, M. \& Şevik, S. (2017) Energy, exergy, economic and environmental (4E) analyses of flat-plate and V-groove solar air collectors based on aluminium and copper. Solar Energy, 158, 259-277.

Aktaş, M., Sözen, A., Amini, A. \& Khanlari, A. (2017) Experimental Analysis and CFD Simulation of Infrared Apricot Dryer with Heat Recovery. Drying Technolgy, 35(6), 766-783.

Aktaş, M., Şevik, S., Dolgun, E.C. \& Demirci, B. (2018) Drying of grape pomace with a double pass solar collector. Drying Technology, 1-13.

Alta, Z.D., Çă̆layan, N., Ezan, M.A. \& Ertekin, C. (2015) Thermal analysis of a solar air heater for drying purposes. Agricultural Engineering International, 193-199.

Azaizia, Z., Kooli, S., Elkhadraoui, A., Hamdi, I., Guizani, A. (2017) Investigation of a new solar greenhouse drying system for peppers. International Journal of Hydrogen Energy, 42, 8818-8826.

Blowmik, H. \& Amin, R. (2017) Efficiency improvement of flat plate solar collector using reflector. Energy Report, 3, 119123.

Cengel, Y.A. \& Ghajar, A.J. (2011) Heat and Mass Transfer: Fundamentals and Applications Fourth Edition in SI Units. McGraw-Hill, New York.

Devecioglu, A.G. \& Oruc, V. (2017) Experimental investigation of thermal performance of a new Solar air collector with porous surface. Energy Procedia, 113, 251-258.

Fudholi, A., Sopian, K., Ruslan, M.H. \&Othman, M.Y. (2013) Performance and cost benefits analysis of double-pass solar collector with and without fins. Energy Conversion and Management, 76, 8-19.

Ghiami, A. \& Ghiami, S. (2018) Comparative study based on energy and exergy analyses of a baffled solar air heater with latent storage collector. Applied Thermal Engineering, 133, 797-808.

Gill, R.S., Singh, S. \& Singh, P.P. (2013) Low cost solar air heater. Energy Conversion and Management, 57, 131-142.

Hernández, A.L. \& Quiñonez, J.E. (2018) Experimental validation of an analytical model for performance estimation of natural convection solar air heating collectors. Renewable Energy, 117, 202-216.

Hosseini, S.S., Ramiar, A. \& Ranjbar, A.A. (2018) Numerical investigation of natural convection solar air heater with different fins shape. Renewable Energy, 117, 488-500.

Kareem, M.W., Gilani, I., Habib, K., Irshad, K. \& Baran Saha, B. (2017) Performance analysis of a multi-pass solar thermal collector system under transient state assisted by porous media. Solar Energy, 158, 782-791.

Karim, M.A., Perez, E. \& Amin, Z.Y. (2014) Mathematical modelling of counter flow v-grove solar air collector. Renewable Energy, 67, 192-201.

Kays, W.M. (1966) Convective Heat and Mass Transfer. McGraw-Hill, New York.

Klein, S.A. (1975) Calculation of flat plate collector loss coefficients. Solar Energy, 17, 79-80.

Lesny, J., Panfil, M., Urbaniak, M. (2018) Influence of irradiance and irradiation on characteristic parameters for solar air collector prototype. Solar Energy, 164, 224-230. 
Naphon, P. (2005) On the performance and entropy generation of the double-pass solar air heater with longitudinal fins. Renewable Energy, 30(9), 1345-1357.

Olimat, A.N. (2017) Study of Fabricated Solar Dryer of Tomato Slices Under Jordan Climate Condition. International Journal of Renewable Energy Development, 6(2), 93-101.

Othman, M.Y.H., Yatima, B., Sopian, K. \& Abu Bakara, M.N. (2005) Performance analysis of a double-pass photovoltaic/thermal (PV/T) solar collector with CPC and fins. Renewable Energy, 30, 2005-2017.

Ozgen, F., Esen, M. \& Esen, H. (2009) Experimental investigation of thermal performance of a double-flow solar air heater having aluminium cans. Renewable Energy, 34, 2391-2398.

Priyam, A. \& Chand, P. (2018) Effect of wavelength and amplitude on the performance of wavy finned absorber solar air heater. Renewable Energy, 119, 690-702.
Saxena, A., Varun \& El-Sebaii, A.A. (2015) A thermodynamic review of solar air heaters. Renewable and Sustainable Energy Reviews, 43, 863-890.

Şevik, S. (2013) Design, experimental investigation and analysis of a solar drying system. Energy Conversion and Management, 68, 227-234.

Tiwari, S. \& Tiwari, G.N. (2017) Energy and exergy analysis of a mixed-mode greenhouse-type solar dryer, integrated with partially covered N-PVT air collector. Energy, 128, 183-195.

Zare, D., Minaei, S., Mohamad Zadeh, M. \& Khoshtaghaza, M.H. (2006)Computer simulation of rough rice drying in a batch dryer. Energy Conversion and Management, 47, 3241-3254.

Zheng, W., Zhang, H., You, S., Fu, Y. \& Zheng, X. (2017) Thermal performance analysis of a metal corrugated packing solar air collector in cold regions. Applied Energy, 203, 938947. 